\title{
The Influence of Radiosonde 'Age' on TRMM Field Campaign Soundings Humidity Correction
}

\author{
Biswadev Roy ${ }^{1}$ \\ Science Systems \& Applications, Incorporated and NASA GSFC \\ Mesoscale Processes Branch, Greenbelt, Maryland 20771
}

\begin{abstract}
Jeffrey B. Halverson
Joint Center for Earth Systems Technology, University of Maryland Baltimore County Baltimore, and NASA GSFC Mesoscale Processes Branch, Greenbelt, Maryland

\section{Junhong Wang}

National Center for Atmospheric Research, Atmospheric Technology Division, Boulder, Colorado 80307
\end{abstract}

November 30, 2002

(submitted to J. Atmos. Oceanic Technol.)

\footnotetext{
${ }^{1}$ Corresponding author address: Code 912, GSFC, Greenbelt, MD 20771. E-mail:

roy@agnes.gsfc.nasa.gov
} 


\title{
Popular summary
}

\section{"The Influence of Radisonde 'Age' on TRMM Field Campaign Soundings Humidity Correction"}

\author{
Biswadev Roy ${ }^{1}$, Jeffrey B. Halverson ${ }^{2}$, and Junhong Wang ${ }^{3}$ \\ ${ }^{1}$ SSAI, Code 912, GSFC, Greenbelt, MD 20771 \\ 2 JCET/UMBC, Code 912, GSFC, Greenbelt, MD 20771 \\ ${ }^{3}$ NCAR/ATD, Boulder, CO 80307
}

Radio-sonde is used for measuring atmospheric parameters such as temperature, relative humdity, and winds. It is essentially an instrument package (sonde) that has sensors to measure temperature, humidity, and winds and are attached to a balloon filled with lighter-than-air gas such as helium Hence as the balloon goes up in the atmosphere it collects data and using a radio it relays the data back to the earth based receiver. We have obtained about 2300 such radio-soundings from the TRMM field campaigns held in the year 1999. The humidity data obtained from the Vaisala radio-sondes were found to be corrupt i.e. during the sounding the atmosphere is actually moist but the radio-sonde is measuring it as "dry". In order to remove this "dry-ness" in the humidity data we have applied some humidity correction procedure. These procedures were developed at the National Center for Atmospheric Research (NCAR) in Boulder, $\mathrm{CO}$ based on some laboratory tests. Some of the correction procedure involves correcting the data based on age of the sonde i.e. error calculated based on the number of days elapsed from the date the package was manufactured from the day of its actual use in the field. We have interestingly found that sensor arm heating error - one of the problems that was independent of age in the correction method of NCAR is actually dependent on the age of the sonde. We have found that after correction of the relative humidity data the available energy due to convection (the energy that drives the atmosphere i.e. helps cloud formation, etc. and as calculated using the radio-sonde data) has increased from before. 


\begin{abstract}
Hundreds of Vaisala sondes with a RS80-H Humicap thin-film capacitor humidity sensor were launched during the Tropical Rainfall Measuring Mission (TRMM) field campaigns in Large Scale Biosphere-Atmosphere held in Brazil (LBA) and in Kwajalein experiment (KWAJEX) held in the Republic of Marshall Islands. Using Six humidity error correction algorithms by Wang et al. (2002), these sondes were corrected for significant dry bias in the RS80-H data. It is further shown that sonde surface temperature error must be corrected for a better representation of the relative humidity. This error becomes prominent due to sensor arm-heating in the first 50-s data.
\end{abstract}




\section{INTRODUCTION}

During the TRMM field campaign, a combined total of 709 soundings were taken over the KWAJFX (R/V Ron Brown) and LBA sites of Rebio Jaru and Rolim de Moura (see Figures 1a, and 1b). These soundings have undergone quality control (Roy and Halverson, 2002) for general use by the scientific community. We expect that the corrected sounding s will provide better estimate of the latent heating budgets in the tropics especially when compared with model-derived and satellite estimates, as well as the characteristics of convective systems (see Halverson et al. 2001). During our quality control we observed a large dry-bias in the Vaisala soundings (see Figure 2) when compared with coincident VIZ soundings launched from nearby stations. To correct these biases we used the empirical polynomial fits and regression equations based on National Center for Atmospheric Research - Atmospheric Technology Division (NCAR/ATD) series of laboratory tests as reported in Wang et al. (2002a), hereafter referred to as W02. We found a consistently good response on application of the algorithm to the present set of soundings. Corrections are done by applying the equations for the temperature-dependence model, modeled ground-check (GC) contamination, basic calibration and daytime sensor arm-heating error (SAHE). In Section 2 this note we describe the sensor RS80-H and how the data were obtained during the TRMM field campaigns. Section 3 describes the procedure adopted for correcting the Vaisala $\mathrm{RH}$ dry bias and the assumptions that we made. Generally it was thought that the sensor arm heating biases are independent of the sonde age but after application of the correction procedure we have found an inherent age- 
dependence. A brief description of the results obtained after correction appear in Section 4. The purpose of this note is to evaluate the RS80-H correction algorithm after application to the TRMM soundings and also to report an agedependent variation of the SAHE which is used in W02 based on Cole and Miller (1995). These evaluation results may be useful for development of a reference radiosonde system as mentioned in Wang (2002b). Because an overall improvement in the RH data is obtained using W02 algorithm hence a brief discussion about the resulting data quality based on the site-mean convectiveavailable potential energy (CAPE) is also given in section 4 . In section 5 we briefly discuss about the RH corrected version 'e' Vaisala sounding products that have been delivered to the Goddard Distributed Active Archive Center (GDAAC).

\section{SENSOR AND DATA DESCRIPTION}

During the TRMM field campaigns relative humidity was measured by use of thin-film capacitive hygristor.. The hygristor measures in the range 0 to $100 \%$ $\mathrm{RH}$ with a $1 \%$ resolution. This sensor has a lag time of 1 -s with $6 \mathrm{~m} / \mathrm{s}$ flow at $1000 \mathrm{mb}$ and at +20 degree $\mathrm{C}$ temperature. Data were obtained using the DigiCORA II model MW-15 ground system and processor. GC parameters are typically measured by an independent set of sensors at the surface. The GC parameters are not used to adjust the sounding's factory determined calibration coefficients. For the case of R/V Ron Brown launches an independent integrated suite for Improved Meteorological Instruments (IMET) as described in Hosom et al. (1995) was used at the surface for obtaining 1-min average data at sonde launch time. Calibration was done by feeding in punched-hole strip during the 
GC procedure. The GC parameters (pressure, temperature, $\mathrm{RH}$, wind-speed and wind direction) are then entered and offsets are computed and recorded in the sounding data file. For the LBA launches at Rebio Jaru and Rolim de Moura hand held psychrometer, thermometer, and wind-measuring instrument was used for GC purpose. The Vaisala RH sensor samples approximately every $1.5 \mathrm{sec}$. A least-squares technique is then used to generate smoothed data at 10 -s temporal resolution. This is done by the Vaisala sounding processing algorithm itself.

There are in all 297 soundings from R/V RHB in the period between July 25, 1999 and September 11, 1999. The sondes were launched every three hours continuously from R/V RHB but were disrupted in the period Aug 19-27, 1999. All R/V RHB data were re-formatted to a consistent LBA format (Roy \& Halverson, 2002). There were 412 soundings performed from the LBA sites of Rebio Jaru and Rolim de Moura. Full time operations at Rebio Jaru and Rolim de Moura did not begin until Jan 24, 1999. Operations were terminated at Rolim de Moura on February 21, 1999 since the equipment was moved to another site. Operations were terminated at Rebio Jaru on Feb 25, 1999. The raw data were subjected to visual check procedure and the Skew-T $\ln \mathrm{P}$ charts were generated for each sounding and were visually inspected to find errors in the data such as super-adiabatic lapse rates, low-level temperature and humidity problems and few other problems such as rapid drying, and rapid heating or cooling. Preliminary quality flagging of the data sets were performed and version ' $d$ ' files were created using a method similar to the TOGA-COARE quality flagging algorithm as mentioned in Loehrer et al. (1996). The NCAR/ATD algorithm mentioned in W02 for RS80-H correction was applied to these version 'd' files. 
Missing data have been flagged and no attempt has been made to substitute missing data with any other estimate.

\section{METHOD}

An overview of the correction algorithm is given in Fig. 10 of W02. A simplified flow-diagram is shown here in Figure 3. A GC correction was performed using Equation 4-10 given in W02:

$U^{\prime}=U_{m}-\Delta U_{G C}^{\prime}$,

where $U_{m}$ is the sonde-measured $\mathrm{RH}$ and $\Delta U_{G C}^{\prime}$ is the GC error measured from an independent instrument. Wherever the GC error values were not recorded we used the modeled GC values given by the sensor aging error (SAE); the SAE were determined using Eq. 4-11 of W02 (Eq. 3 below). The resulting GC. correction is added to the entire sounding RH data and then the ambient temperature-dependent error model -1 (TD1), basic-calibration model error (BC), chemical contamination correction (CC), temperature-dependent correction model -2 (TD2) and 10-s Daytime SAHE, and DSAH10-s corrections are done using the Equations 5-1H, 4-6H, 4-1H, 5-2H, 4-7 and 4-8 respectively of W02

$$
\begin{aligned}
& \quad T D 1=-0.61+0.9561 U^{\prime}+\left(0.031+0.00359 U^{\prime}\right) t \\
& +\left(-0.00033-0.0000727 U^{\prime}\right) t^{2} \\
& +\left[\left(0.0000014-(9.6 E-8) U^{\prime}\right] t^{3}\right. \\
& +\left[(-3.1 E-09)+(5.431 E-09) U^{\prime}\right] t^{4} \\
& S A E=-0.1638+1.4766 d-0.2257 d^{2} \\
& B C=H_{0}+H_{1} U+H_{2} U^{2}+H_{3} U^{3} \\
& \text { where } \\
& H_{0}=-0.3019, H_{1}=-0.0081, H_{2}=0.0011, \text { and } H_{3}=-1.23 E-05
\end{aligned}
$$




$$
\begin{aligned}
& C C=\left[k h_{0}+\left(k h_{1}\right) d+\left(k h_{2}\right)\left(d^{2}\right)+\left(k h_{3}\right)\left(d^{3}\right)+\left(k h_{4}\right)\left(d^{4}\right)\right] x \\
& {\left[p h_{0}+\left(p h_{1}\right)(U)+\left(p h_{2}\right)\left(U^{2}\right)+\left(p h_{3}\right)\left(U^{3}\right)\right]} \\
& \text { where, } \\
& k h_{0}=0.018866, k h_{1}=1.978206, k h_{2}=-1.34278, k h_{3}=0.36915724 \\
& k h_{4}=-0.03241, p h_{0}=1.6994, p h_{1}=0.1368, p h_{2}=-0.0018, p h_{3}=1.4105 E-05 \\
& T D 2=\frac{U_{c}+0.61-0.031 t+0.00033 t^{2}+0.0000014 t^{3}+(3.1 E-09) t^{4}}{0.9601+0.000359 t-0.000085 t^{2}+(9.3 E-08) t^{3}+(6.931 E-09) t^{4}} \\
& S A H E=U_{s r}-\frac{U_{s r} e_{s}\left(T_{s r}\right)}{e_{s}\left(T_{s s}\right)} \\
& D S A H_{i}=(S A H E) e^{-t_{i} / \tau}
\end{aligned}
$$

where the GC value of $\mathrm{RH}\left(U^{\prime}\right)$ is used from (1) to compute TD1 in (2). The ambient temperature $t$ is used from the sounding. The serial numbers for each sounding was obtained from the manufacturer (Vaisala, Inc.). Age (d) of the sonde (in year) was calculated using the sonde serial numbers. In this study the age of sonde ranged from 0.06 year to 2.07 years. Because the basic calibration of each sensor is done during the production process and using an averaged calibration model, Wang et al. (2002a) used an accurate test chamber and found there were errors associated with the average model at various RH points. Hence BC error computed using (4) is used for RH correction which in turn become input to the contamination correction model (see Fig. 3). The contamination is caused mainly due to occupation of non-water molecules at the binding sites hence reducing the ability of water molecule absorption by the polymer. This contamination process become prominent with age of the sonde due to a longer exposure to the packaging material that out-gasses on to the substrate. A polynomial fit for an average approximation of the $\mathrm{RH}$ error due to this contamination (CC) process with sonde age (d) is mentioned in W02 and is given here in (5). After this the CC quantity is brought back to an $\mathrm{RH}$ value at 
ambient temperature using (6) and then the TD and SAE are added to get an $\mathrm{RH}$ value which is not yet corrected for the radiation induced SAHE. This armheating error is calculated only for the first 5 levels of sounding. This is limited to the first 50-s since the thermal time constant $(\tau)$ of the RH sensor is 13 seconds (as in $7 \mathrm{~b}$ ) and it is expected that the RS80-H will equilibrate within a period which is 4 times the thermal constant. SAHE is computed using the surface reference $\mathrm{RH}\left(\mathrm{U}_{\mathrm{sr}}\right)$, and using the saturated vapor pressure once calculated using the sonde surface level temperature $\left(T_{s s}\right)$ and another time using the surface reference temperature measured using an independent instrument $\left(\mathrm{T}_{\mathrm{sr}}\right)$. The saturation vapor-pressure data appearing in (5) are computed using method as mentioned in Bolton (1980). The surface $\mathrm{RH}$ value as measured by the sonde is corrected using the GC procedure and is used to compute the surface vapor pressure appearing in the denominator of term 2 of (5). No model-based correction is imparted to the sonde surface $\mathrm{RH}$ value. It is also assumed that there were no occurrence of low-level inversion during the day-time sounding periods and since the sonde $\mathrm{RH}$ at 10-s and above are corrected using the W02 algorithm, it is then expected that the error in a well-mixed boundary layer (during day time) will only be caused due to radiation-induced sensor armheating. The choice for use of the sonde registered surface $\mathrm{RH}$ value is made since the sonde measured surface $\mathrm{RH}$ value should ideally remain constant with height within the well-mixed boundary layer. For SAHE calculations that are separated by approximately 10-s $\left(t_{\mathrm{I}}\right)$ we have the value of damping factor $\exp (-$ $\left.t_{i} / 13\right)$ in $(7 b)$ ranging from 0.46 to 0.02 . 


\section{RESULTS}

\section{a. Overall $R H$ correction}

We have incorporated humidity correction for almost all levels and for all soundings obtained from the three TRMM field sites following the algorithm W02 as shown in Figure 3. The average daytime, and night-time vertical profiles of the uncorrected minus corrected $\mathrm{RH}$ values are compared. These profiles are shown for each of the sites in Figures $4 \mathrm{a}, 4 \mathrm{~b}$, and $4 \mathrm{c}$. The day-time corrections include the SAHE modification to the first 50 -s of the sounding, or up to about $250 \mathrm{~m}$ above ground level. From Figures 4 it is evident that moisture loading due to the current algorithm is prominent in the mid-levels and reach maximum in the $200-100 \mathrm{mb}$ region for all the three sites. Figures $5 \mathrm{a}$ and $5 \mathrm{~b}$ show the total counts of observations for various age of the respective sonde. For Rebio Jaru site maximum observations were made with sondes in the age group 0.08 to 0.12 years, and for Rolim de Moura site maximum observations were also made in the sonde age ranging between 0.08 to 0.12 years but there were few soundings that were manufactured almost 2 years prior to their use. Maximum observations made from R/V RHB were obtained from sondes that were manufactured in the range 0.19 to 0.33 years prior to their use.

b. Variation of mean correction parameters with sonde age

Figure 6 shows the variation of GC, CC, DSAH-10s, with sonde age, and the mean of the uncorrected minus corrected $\mathrm{RH}$ as a function of sonde age. Sixth order polynomial fit for each type of error is shown in Figure 6 . We have the following results: (a) The mean modeled GC increases with age, (b) The mean of CC correction varies with age, (c) The mean contamination, and mean DSAH10 s are found to vary in a cyclic manner with age. The CC correction is 
dependent on age of the sonde as shown in W02 and Eq. (5) here. However we have investigated into the reason why the SAHE and hence the DSAH-10s vary in a cyclic fashion with the age of the sonde.

c. Variation of SAHE with age

The mean SAHE and DSAH-10s are found to have slope 1.92. Figure 6a shows the age-dependent variation of mean SAHE and DSAH-10s for those that are computed using all three stations' data. It is seen that both SAHE and as such DSAH-10s bear a cosine function of age. The period is noted as close to 2 years. A third-order polynomial (spline-fit) of SAHE and DSAH-10s with age could be written as,

$$
\begin{array}{r}
S A H E=2.43 d^{3}-7.6 d^{2}+5.08 d+0.3 \\
D S A H-10 s=0.96 d^{3}-2.95 d^{2}+1.88 d+0.2
\end{array}
$$

A closer look suggests that the reference temperature at the surface and the sonde surface temperature used for calculating the surface saturation vapor pressure in (5) gives rise to such a sinusoidal variation of SAHE with age of sonde. Evaluating the ratio $\frac{e_{s}\left(T_{s r}\right)}{e_{s}\left(T_{s s}\right)}$ in (5) by using the Bolton (1980) method and using a common reference surface pressure the ratio of vapor pressure

$$
\frac{e_{s r}}{e_{s s}}=\frac{\exp \left\{\left(T_{s r} a\right) /\left(T_{s r}+b\right)\right\}}{\exp \left\{\left(T_{s s} a\right) /\left(T_{s s}+b\right)\right\}}
$$

or,

$$
\log _{e}\left(\frac{e_{s r\left(T_{s r}\right)}}{e_{s s}\left(T_{s s}\right)}=\frac{a\left(T_{s r}-T_{s s}\right)}{\left(T_{s r}+b\right)\left(T_{s s}+b\right)}\right.
$$

where $a=17.67$, and $b=243.5$. It is evident from (11) that the ratio of saturation vapor pressure in (5) depends upon the differences in measured surface temperatures. Figure $7 \mathrm{~b}$ shows the variation of difference between surface 
independently measured temperature and the sonde surface temperature with sonde age. The nature of variation between the temperature error and SAHE variation with age are just opposite (c.f. Figures 7a, and 7b). Hence a decrease in the temperature error will increase the SAHE error in RH and vice-versa as in (5). If we represent the surface reference temperature and the surface sonde temperature as function of age and with a frequency $\omega$

$$
\begin{aligned}
& T_{r s}=B_{1} \operatorname{Cos}\left(\omega d+\phi_{1}\right) \\
& T_{s s}=B_{2} \operatorname{Cos}\left(\omega d+\phi_{2}\right)
\end{aligned}
$$

and take the difference in temperature as a cosine function of age

$T_{r s}-T_{s s}=A \operatorname{Cos}(\omega d+\phi)$

then,

$$
T_{r s}=B_{2} \operatorname{Cos}\left(\omega d+\phi_{2}\right)+A \operatorname{Cos}(\omega d+\phi)
$$

re-arranging and using the identity $\operatorname{Cos}\left[2\left(\omega d+\phi_{2}\right)\right]=\left[2 \operatorname{Cos}^{2}\left(\omega d+\phi_{2}\right)-1\right]$ and simplifying this further for condition $\phi_{2} \approx \phi$ we could write the denominator of (11) as

$$
\left(T_{s r}+b\right)\left(T_{s s}+b\right)=P \operatorname{Cos}\left(\omega d+\phi_{3}\right)
$$

hence the right hand side of (11) could be written in terms of the modified amplitude and phase

$\frac{a\left(T_{s r}-T_{s s}\right)}{\left(T_{s r}+b\right)\left(T_{s s}-b\right)}=\frac{a A \operatorname{Cos}(\omega d+\phi)}{D \operatorname{Cos}\left(\omega d+\phi_{3}\right)+K}=P^{\prime} \operatorname{Cos}\left(\omega d+\phi_{4}\right)$

where $K=b^{2}+\frac{B_{2} A}{2}$

From (17) it is evident that the ratio behaves as a cosine function with sonde age but with a combined phase and amplitude. The mean surface temperature error could be approximately represented as a function of sonde age using a spline-fit of the data as follows: 


$$
T_{r s}-T_{s s}=-0.3 d^{3}+0.9 d^{2}-0.7 d+0.023
$$

\section{d. Improvement in CAPE}

The convective available potential energy (CAPE) was computed using the uncorrected soundings and once again after correcting RH data using W02 algorithm. CAPE is the measure of maximum work done by buoyancy and is obtained by integrating the differences in the virtual temperature of parcel $\left(\mathrm{T}_{\mathrm{v}}\right.$ parcel $)$ and that of surrounding $\left(\mathrm{T}_{\mathrm{v} \text {-surr }}\right)$ over all pressure levels in the region between the level of free convection (LFC) - where the parcel become positively buoyant and the level of neutral buoyancy (LNB) - the height at which the parcel regains stability as mentioned in Bohren and Albretch (1998):

$$
C A P E=-R_{d} \int_{L F C}^{L N B}\left(T_{\nu-\text { parcel }}-T_{\nu-s u r r}\right) d \ln P
$$

The CAPE values show a significant increase after W02 based correction is applied hus enhancing the site-mean values. Table I gives the quantitative information about the CAPE comparison between the old and new sets.

\section{SUMMARY}

We have successfully applied the recently published W02 system-bias correction algorithm to all Vaisala soundings obtained during the TRMM field campaigns. The day-time and night-time differences in the error (uncorrected minus corrected) RH mean profiles for Rebio-Jaru and Rolim de Moura stations (LBA sites) are found to be small when compared with similar profiles obtained from an oceanic KWAJEX sounding site (R/V RHB). A sonde age (0.06 to 2.06 years) versus height (up to $650 \mathrm{mb}$ level) plot of corrected minus uncorrected specific humidity is shown in Figure 8 . It is apparent from Figure 8 that more 
moisture loading and drying is carried out by W02 algorithm at lower levels than at mid-levels and the magnitude of correction increase with age of the sonde. However, with sondes aged close to 2 years moist bias correction is imparted. Exact reason for this reversal needs to be known. The timely publication of W02 algorithm and its simplicity helped enabling us to perform dry-bias correction on all the RS80-H data The enhanced CAPE values suggest that the soundings represent the LBA and oceanic KWAJ regions in a more realistic manner. Humidity corrections might lead to more efficient mesoscale analysis in line with the large-scale improvements already observed in the TOGA COARE data (Ciesielski et al., 2002). However, a surface temperature correction is advisable in order to solve for the problems that is found with the quantitative SAHE estimation. To check for accuracy of the upper-air data it is advisable that the upper-air corrected $\mathrm{RH}$ profiles be compared with some other independent measurements taken during the period of TRMM field campaign. The version 'e' files with about 367, 462 corrected $\mathrm{RH}$ observations as per W02 algorithm have been posted to Goddard Distributed Active Archive Center (GDAAC).

\section{Acknowledgments}

The authors wish to acknowledge the support of Dr. Ramesh Kakar, NASA Headquarters. One of the authors (BR) wishes to thank Dr. Dean Duffy and Dr. George Huffman of the GSFC Laboratory for Atmospheres for reviewing the manuscript and to Mr. Ken Goss of Vaisala Inc. for providing the sonde serial numbers. We also wish to the TRMM Project Scientist Dr. Robert F. Adler at NASA/GSFC for his continued support in this program. 


\section{REFERENCES}

Bohren, Craig, F., and Bruce A. Albretch, 1998: Atmospheric Thermodynamics, Oxford University Press, 402 pp.

Bolton, David, 1980: The computation of equivalent potential temperature, Mon. Wea. Rev., 108, 1046-1053.

Ciesielski, Paule, E., Richard H. Johnson, Patrick T. Haertel, and Junhong Wang, 2002: Improved large-scale analyses and forcing fields for TOGA COARE with humidity corrected data, J. Atmos. Sci. (submitted).

Cole, H., and E. Miller, 1995: A correction for low-level radiosonde temperature and relative humidity measurements. Preprints, Ninth Symp. On Meteorological Observations and Instrumentation, Charlotte, NC, Amer. Meteor. Soc., 32-36.

Halverson, J.B., T. Rickenbach, B. Roy, H. Pierce, and E. Williams, 2001: Environmental characteristics of convective systems during TRMM-LBA, Mon Wea. Rev., 130, No. 6, 1493-1509.

Hosom, David, S., Robert A. Weller, Richard E. Payne, and Kenneth E. Prada, 1995: The IMET (Improved Meteorology) ship and buoy systems, J. Atmos. Oceanic Technol., 12, 527-540.

Loehrer, Scot, M., Todd A. Edmunds, and James, A. Moore, 1996: TOGA COARE upper air sounding data archive: development and quality control procedures, Bull. Amer. Meteor. Soc., 77, 2651-2671.

Roy, B. and J.B. Halverson, 2002: On quality control procedures being adopted for TRMM LBA and KWAJEX soundings data sets. Proceedings, AMS Symposium on Observations, Data Assimilation, and Probabilistic Prediction, Orlando, Florida, 13-17 January, 2002 
Wang Junhong, Harold L. Cole, David J. Carlson, Erik R. Miller, and Kathryn Beierle, 2002a: Corrections of humidity measurement errors from the Vaisala RS80 Radiosonde-Application to TOGA COARE data, J. Atmos. Oceanic Technol., 19, 981-1002.

Wang, Junhong, 2002b: Understanding and correcting humidity measurement errors from Vaisala RS80 and VIZ radiosondes, Radiosonde workshop, Hampton University, Virginia, 21-23 May, 9 pp.

\section{FIGURE CAPTIONS}

Figure 1. The Vaisala sites are marked with an 'X'.a) Locations of Rebio-Jaru and Rolim de Moura Vaisala sounding sites shown with respect to other LBA VIZ sounding sites in Brazil during January-February, 1999. (b) Location of R/V RHB Vaisala sounding site during KWAJEX at approximately $8.36^{\circ} \mathrm{N}, 67.73^{\circ} \mathrm{E}$ held during JulySeptember, 1999.

Figure 2. A comparison plot for the mean profiles of Vaisala measured RH and Temperature values and VIZ measured RH and temperature values. This plot was obtained after averaging the profile for the entire LBA period. Note the reversal of RH bias in the mid-level.

Figure 3. The system-bias correction algorithm flow-chart based on W02.

Figure 4. (a) Profiles of mean daytime and night-time differences between the uncorrected and corrected RH data for Rebio Jaru (b) Rolim de-Moura and (c) RV/RHB site.

Figure 5 (a) Bar-charts showing observation counts at various sonde age for Rebio Jaru, site and, (b) for Rolim de Moura site. 
Figure 6 A Plot showing the variation of GC, CC, SAE, SAHE, and the uncorrected minus corrected RH data with sonde age. A sixth order polynomial fit is shown for each of the correction parameter involved in W02.

Figure 7 (a) Variation of mean SAHE (and DSAH10-s) with sonde age, (b) Variation of mean of the difference of surface reference temperature and sonde surface temperature with age of sonde.

Figure 8 Shows the sonde age-height plot of specific humidity corrections $(\mathrm{g} / \mathrm{Kg})$ imparted to the RS80-H data using W02 algorithm. Note that the sign of correction delta changes from negative to positive for the sonde age exceeding 1 year. 

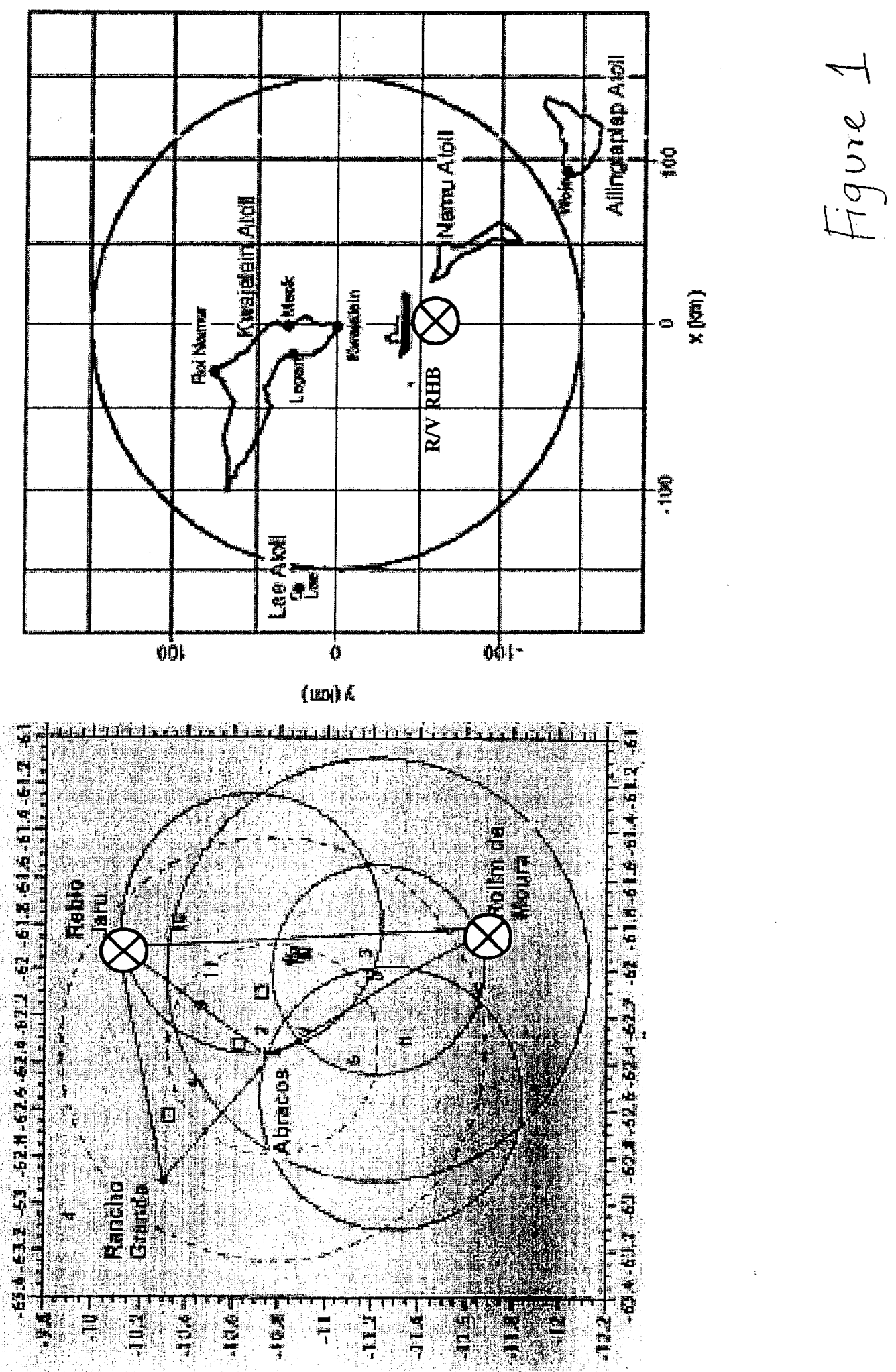


$\gamma$
$y$
5
in
15

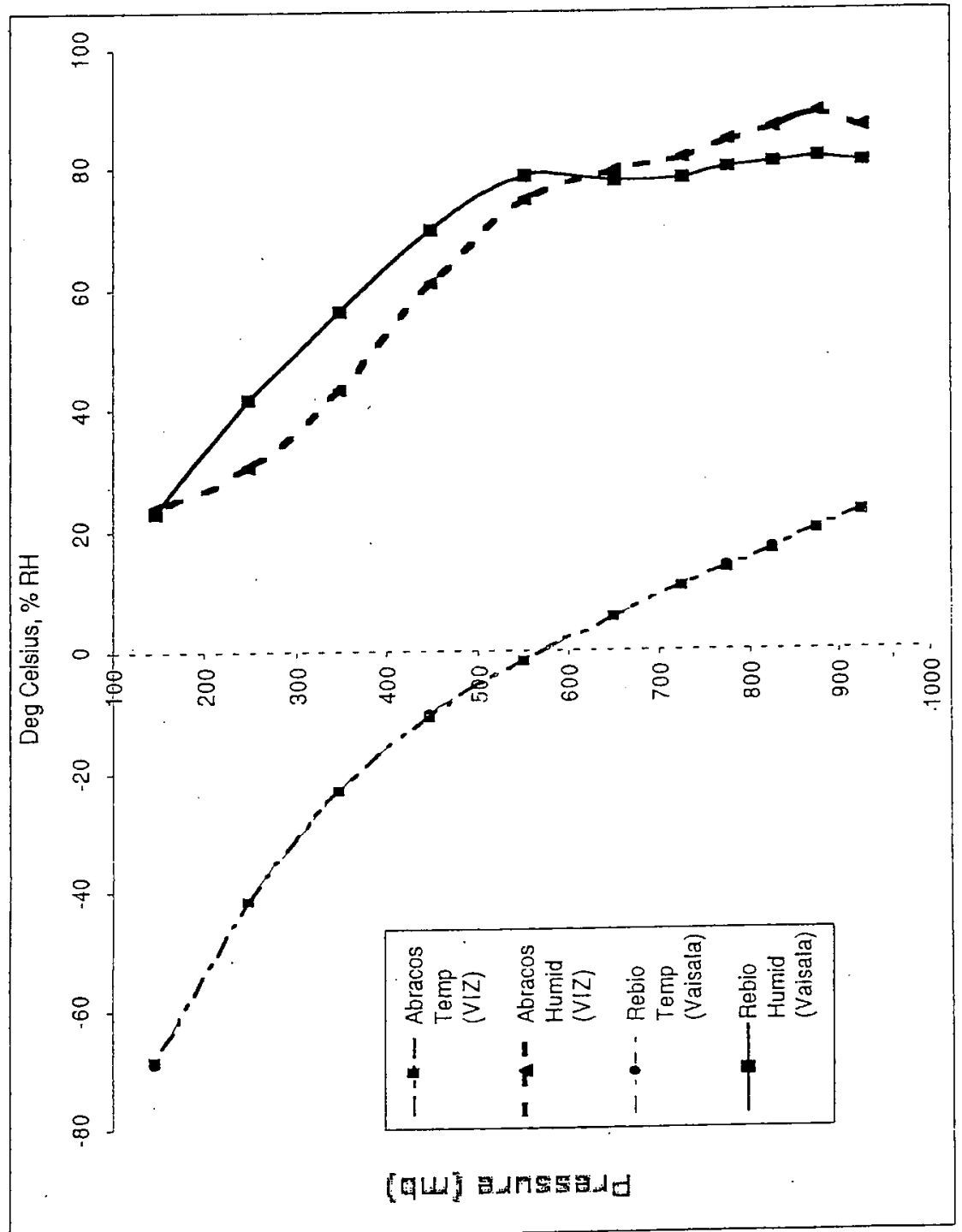




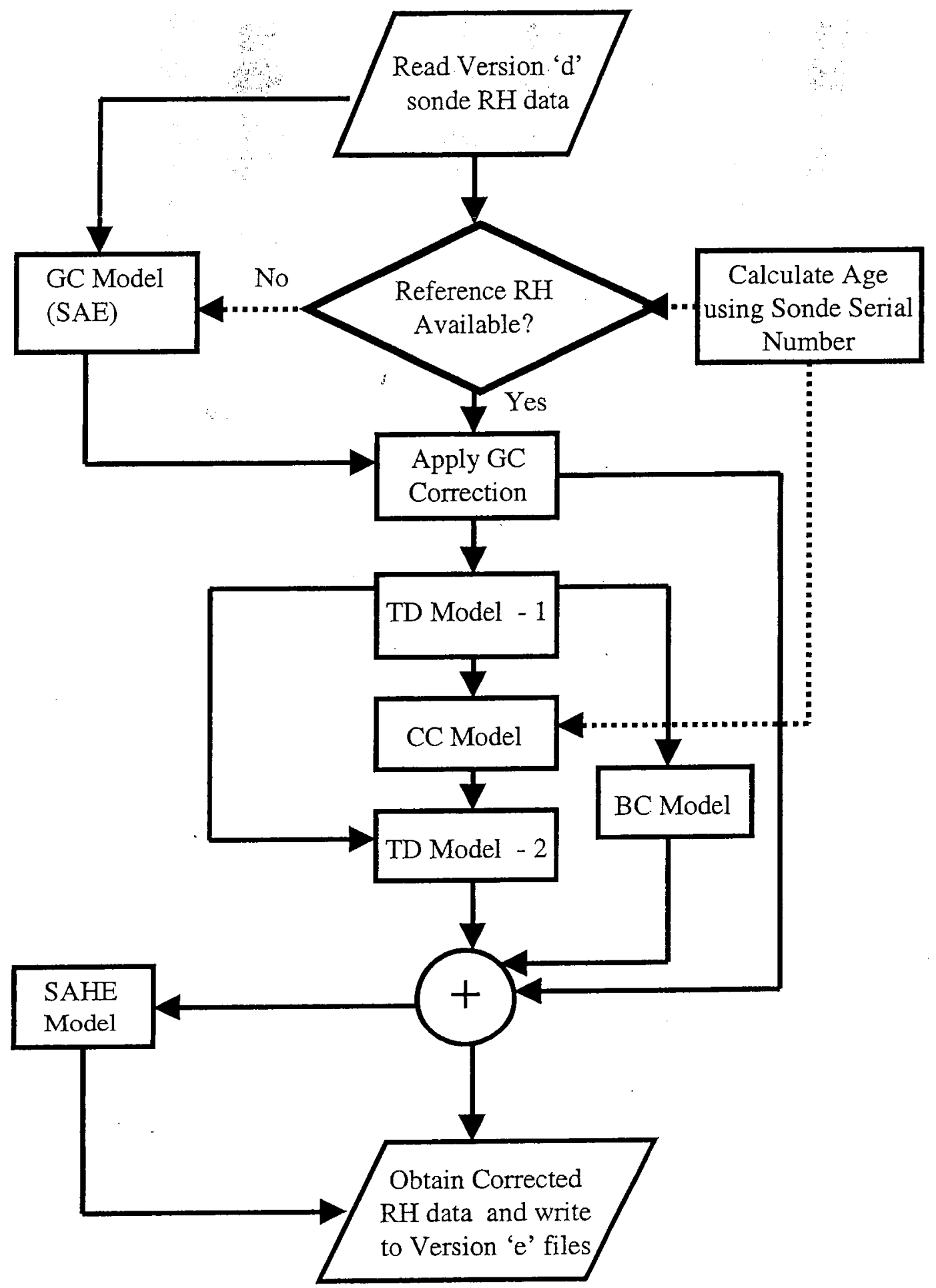



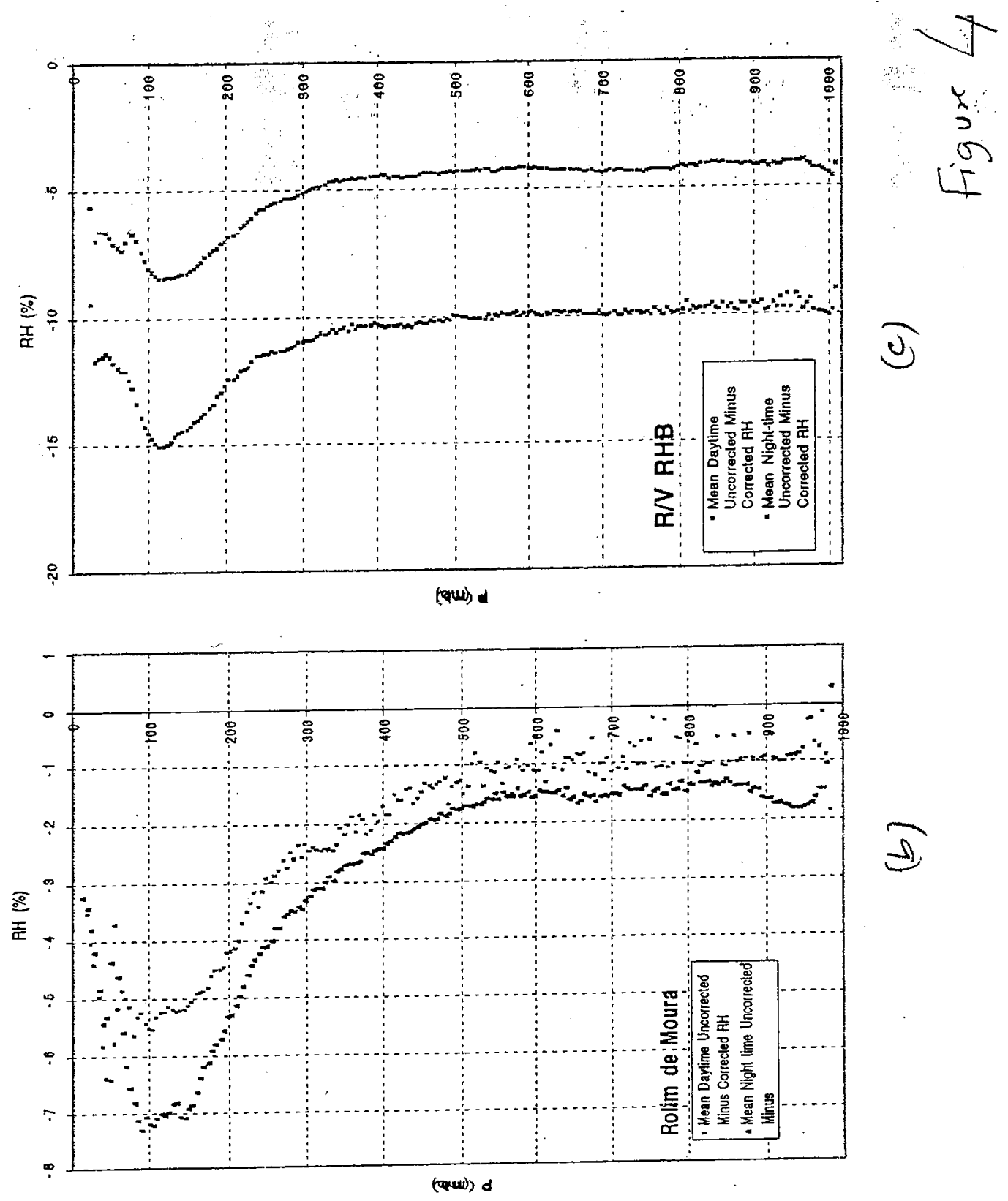

3

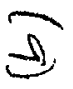

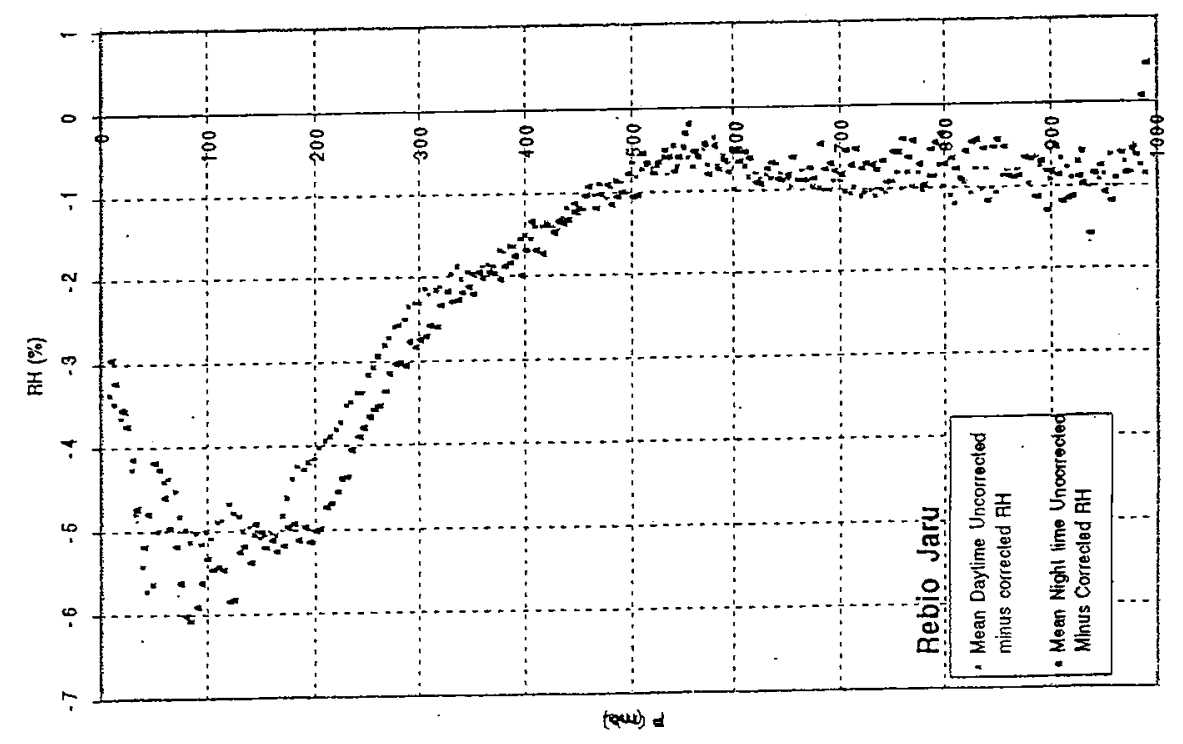

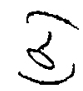


figue 5
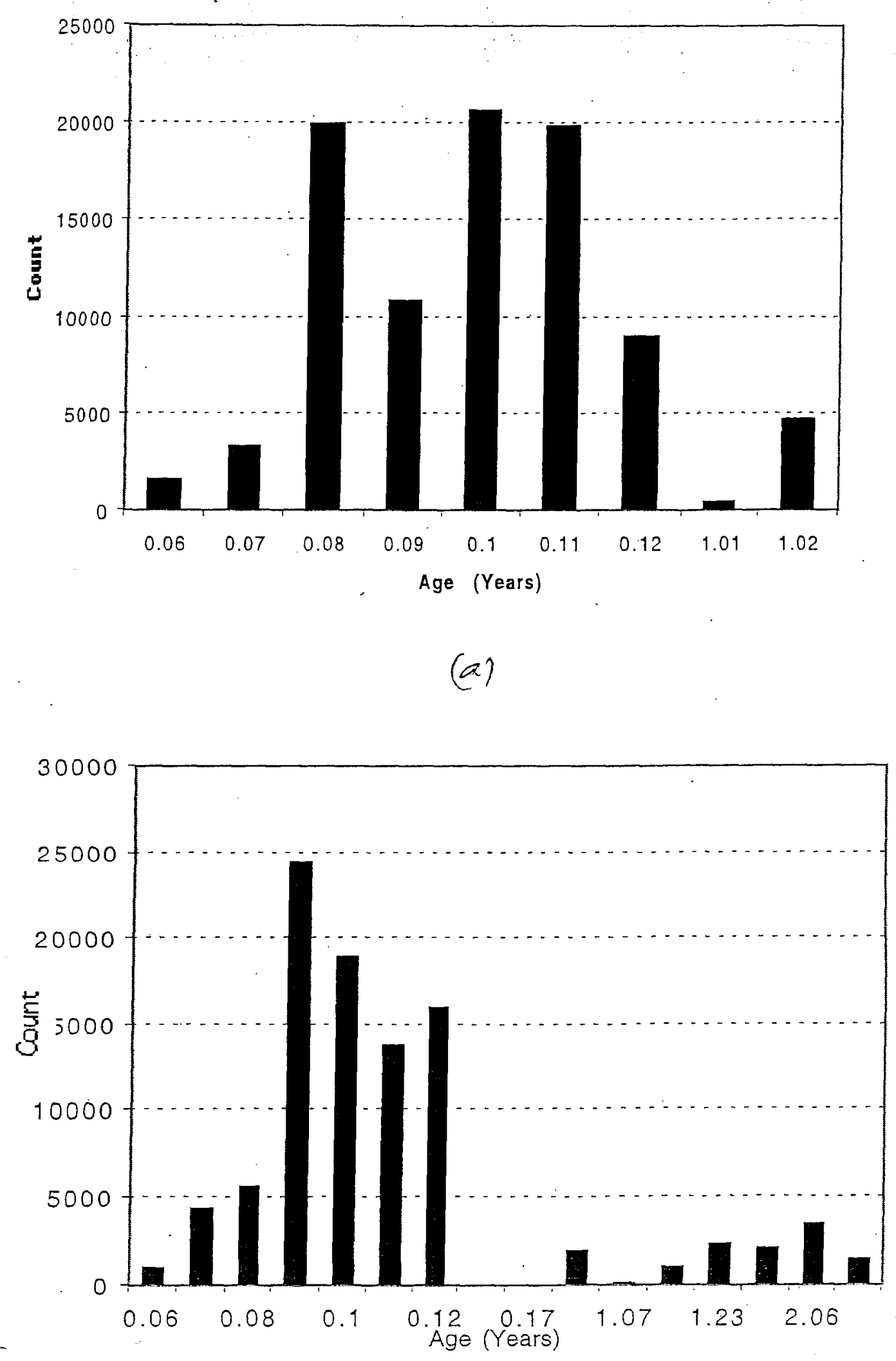
$\frac{9}{5}$

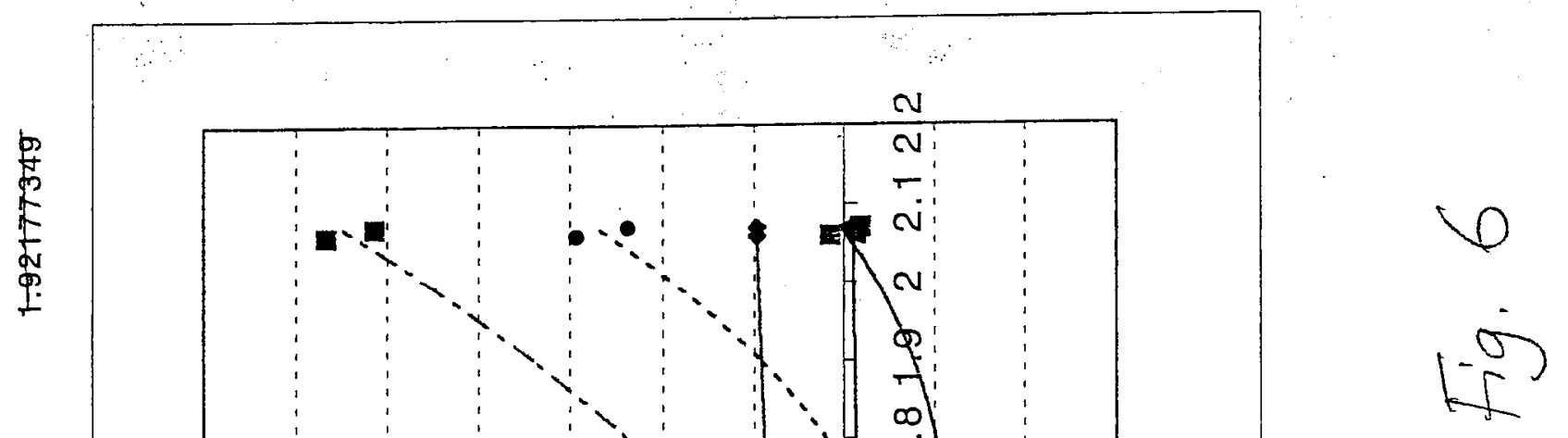


Figure
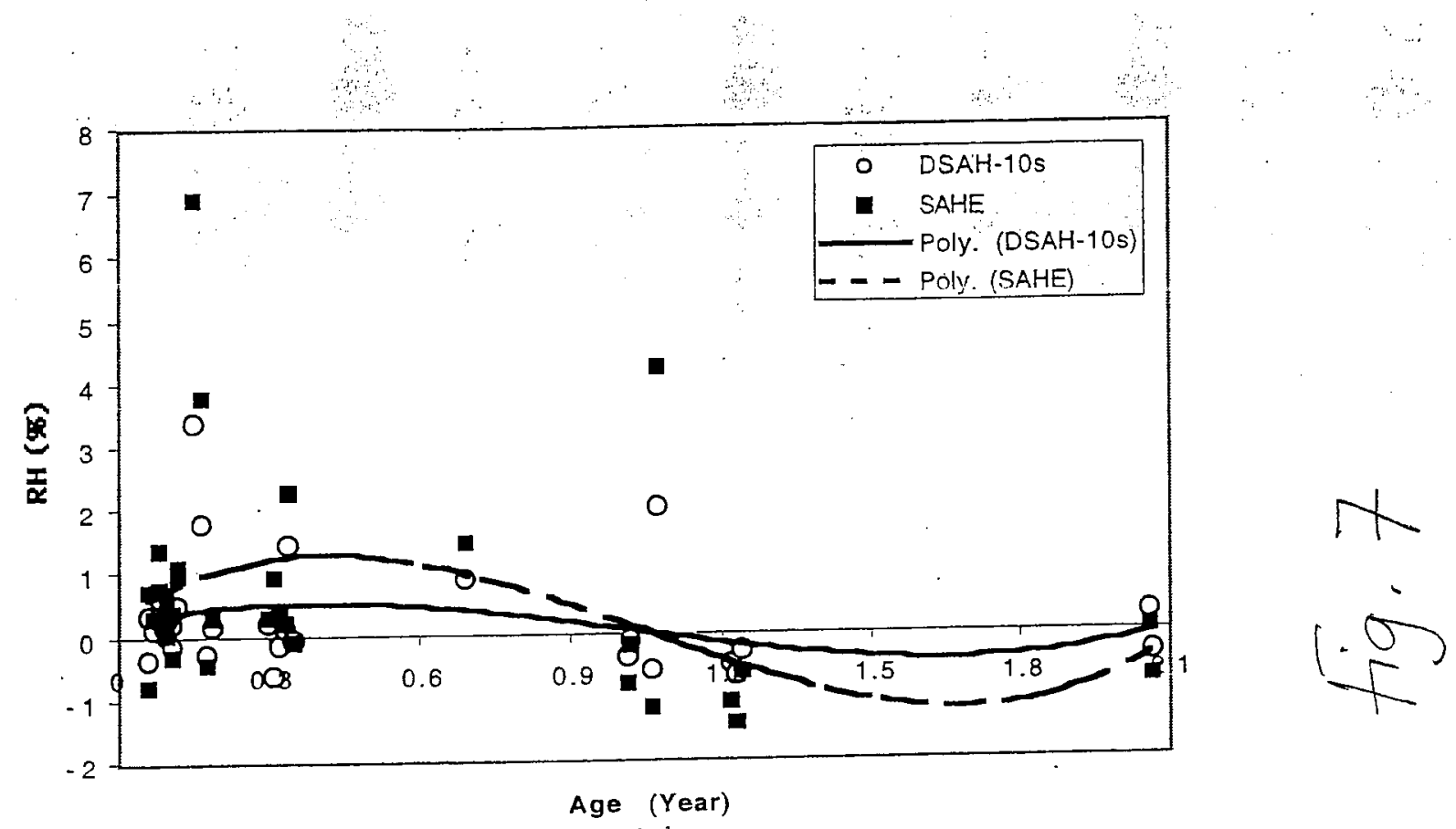

(a)

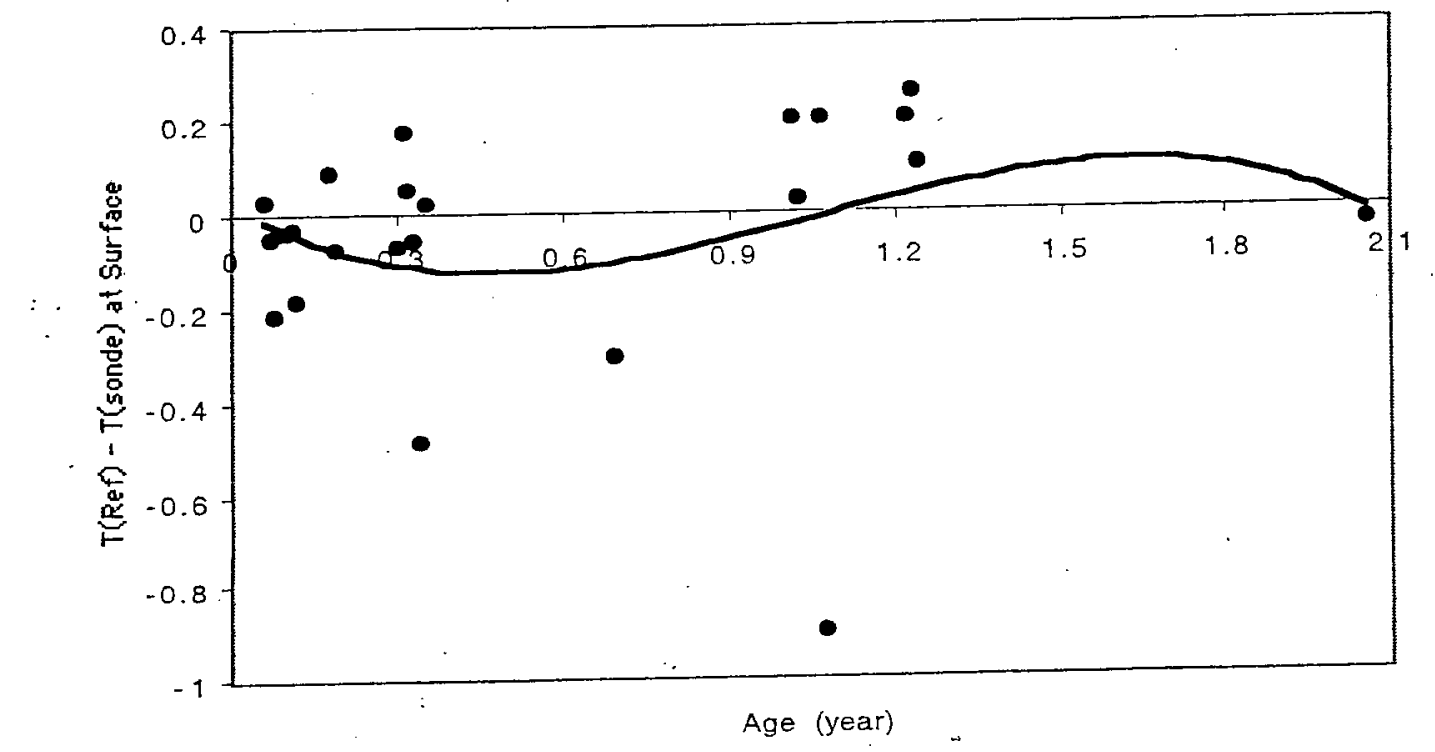

(b) 


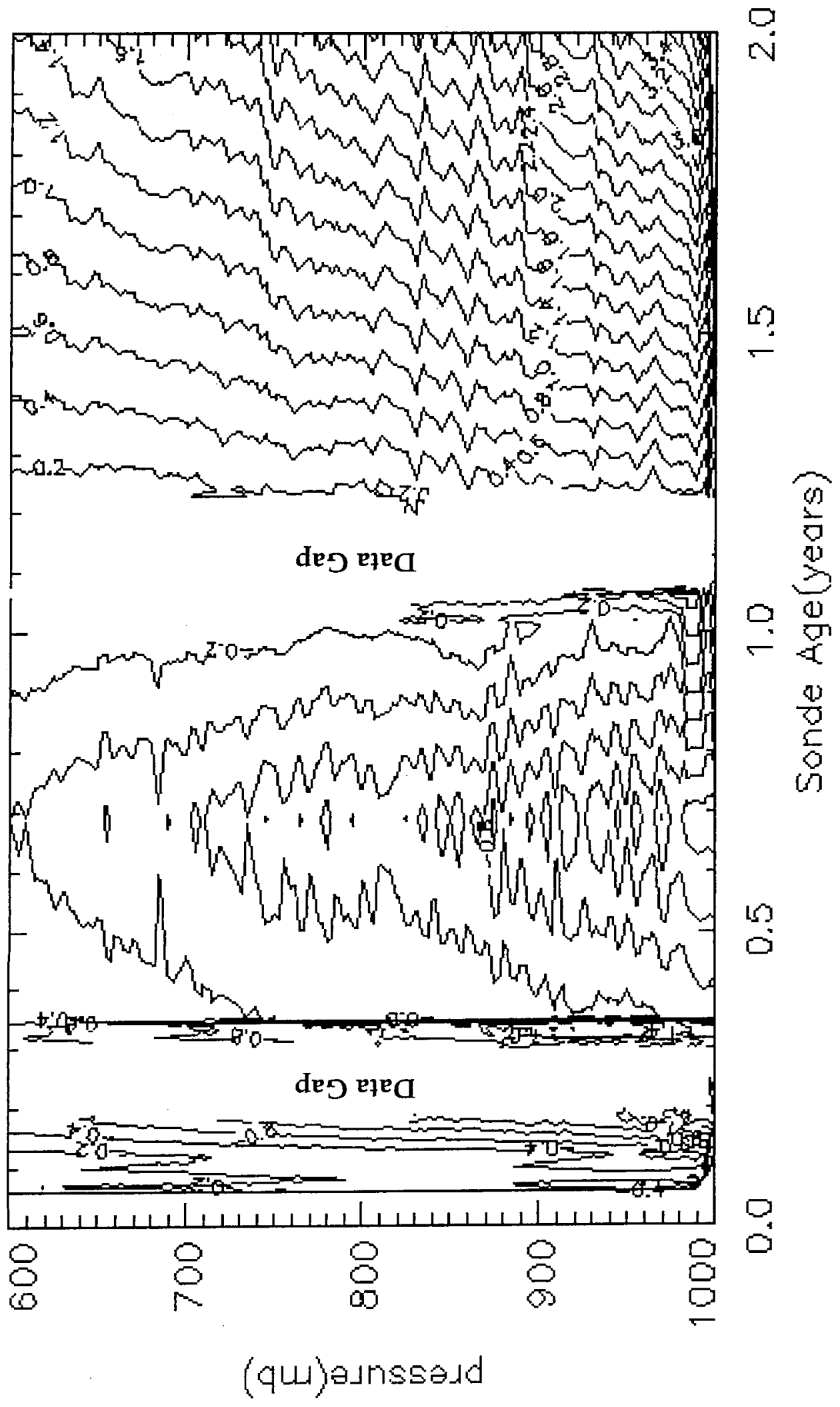

$\infty$ $\frac{2}{25}$ 

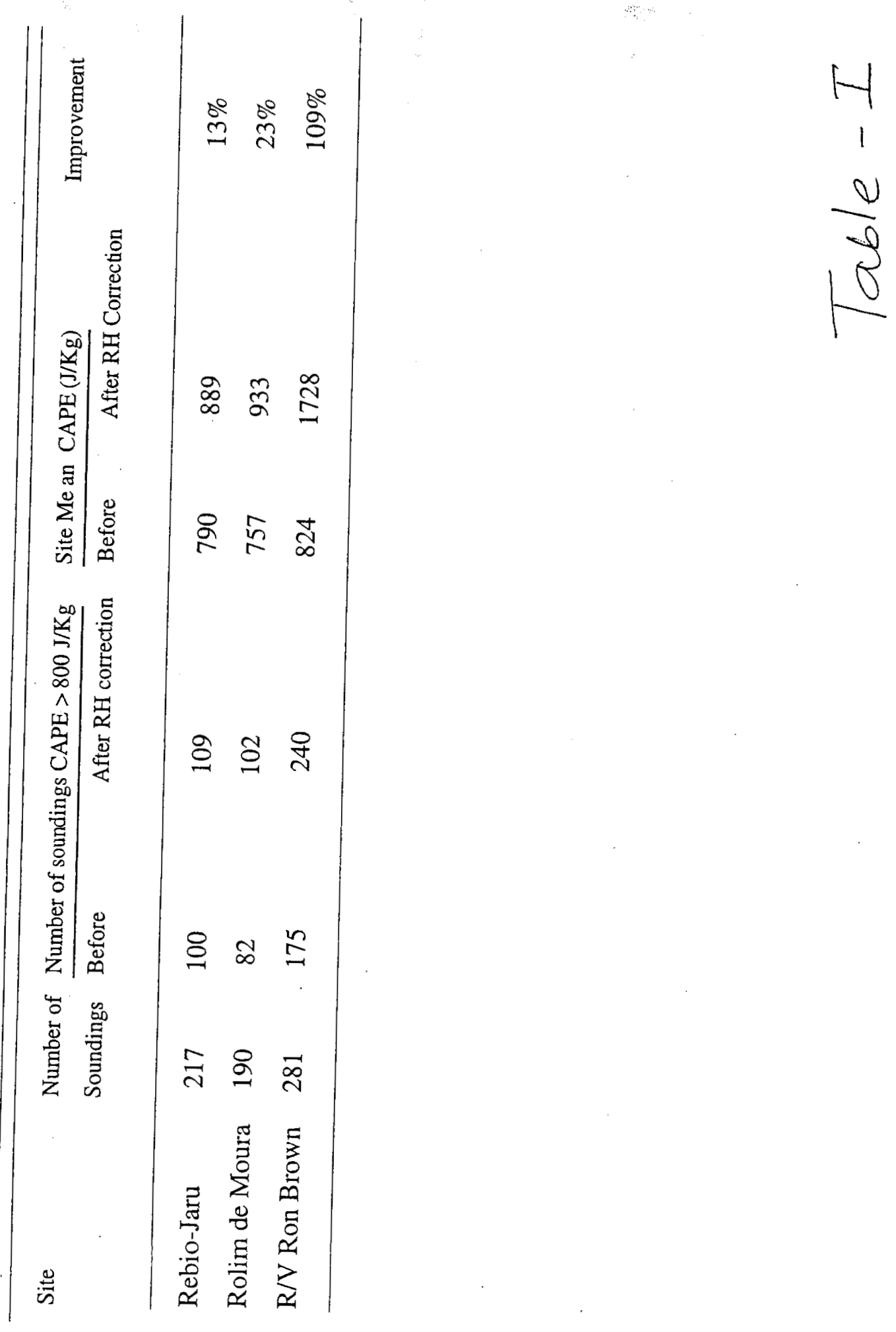